\title{
Avaliação do potencial de integração entre o uso e ocupação do solo e o transporte de carga em um recorte urbano de São Paulo
}

\author{
Thiago Canhos Montmorency Silva ${ }^{1}$, Karin Regina de Castro Marins ${ }^{2}$ \\ ${ }^{1}$ Escola Politécnica da Universidade de São Paulo, Departamento de Engenharia Civil, thiagocanhos@gmail.com \\ ${ }^{2}$ Escola Politécnica da Universidade de São Paulo, Departamento de Engenharia Civil, karin.marins@usp.br
}

Recebido:
14 de março de 2018
Aceito para publicação:
21 de janeiro de 2019
Publicado:
31 de agosto de 2019
Editor de área:
Renato Lima

\section{Palavras-chaves:}

Transporte Urbano de Carga;

Uso e Ocupação do Solo;

Densidades Urbanas;

Modelagem Urbana;

Freturb.

\section{Keywords:}

Urban Freight Transport;

Land Use;

Urban Densities;

Urban Modeling;

Freturb.

DOI:10.14295/transportes.v27i2.1620

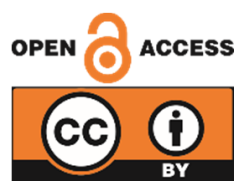

\begin{abstract}
RESUMO
O objetivo desse artigo é realizar uma avaliação integrada entre o transporte urbano de carga e o uso e ocupação do solo, por meio da aplicação do modelo Freturb em um recorte urbano na cidade de São Paulo. Os resultados indicaram haver interdependências entre os parâmetros do transporte urbano de carga (tipos de veículos comerciais, condições de carga e descarga e quantidades de movimentações) e do uso e ocupação do solo (perfil econômico, dimensões dos estabelecimentos alimentícios, número de empregos e de habitantes), revelando quais aspectos do transporte urbano da carga impactam diretamente no uso do espaço urbano e quais elementos do uso e ocupação do solo condicionam aspectos da logística e do tráfego urbano, em um contexto urbano brasileiro. Entende-se que as inter-relações demonstradas sejam fundamentais para aprimorar políticas urbanas relacionadas à mobilidade urbana e ao uso e ocupação do solo, ao fomentar o planejamento e a gestão intersetoriais e interdisciplinares em cidades brasileiras.
\end{abstract}

\section{ABSTRACT}

The objective of this study is to perform an integrated assessment between urban freight transportation and land use, by applying the Freturb model in an urban area in the city of São Paulo. The results indicated the interdependencies between the parameters of urban freight transport (types of vehicles, loading and unloading conditions and quantities of goods movements) and land use (economic profile, dimensions of the foods establishments, number of jobs and of inhabitants), revealing which aspects of urban freight transport directly impact the use of urban space and which elements of land use affect aspects of logistics and urban traffic, in a Brazilian urban context. Such interrelationships are fundamental to improve urban policies related to urban mobility and land use, by fostering intersectoral and interdisciplinary planning and management in Brazilian cities.

\section{INTRODUÇÃO}

Nas áreas urbanas, há uma tendência progressiva de adensamento populacional, incentivo ao uso misto e, ainda, incremento de espaços urbanos restritos e onerosos (Marins e Romero, 2012; Silva e Marins, 2014; Dablanc e Frémont, 2015). Por outro lado, associado ao aumento das taxas de consumo de produtos e serviços, há, nitidamente, o incremento da demanda pelo transporte de mercadorias e, consequentemente, o aumento da quantidade de veículos urbanos de carga utilizando o sistema viário. Assim, as grandes movimentações de carga urbana estão relacionadas ao acelerado processo de urbanização, aos modos de produção e de consumo e ao 
desenvolvimento econômico urbano. Entretanto, os impactos das movimentações de carga urbana são de difícil mensuração, a coleta de seus dados estatísticos é restrita e o tema, em geral, é superficialmente tratado em políticas e projetos de desenvolvimento urbano.

Para subsidiar a inserção do transporte urbano de carga como elemento de planejamento urbano, é fundamental compreender a relação da carga com o uso e ocupação do solo e a densidade urbana. De acordo com Marins e Romero (2012), o uso e a ocupação do solo moderam o volume de passageiros do sistema de transporte público e a configuração da rede de transporte influi, simultaneamente, na forma de ocupação e no uso do solo. Fazendo uma associação com o transporte urbano de carga, o raciocínio é próximo: o uso e ocupação do solo condicionam a densidade da movimentação da carga urbana; e o sistema de carga urbana, por sua vez, influencia na configuração espacial urbana e na sua utilização.

A otimização da infraestrutura urbana, seja ela para transporte de pessoas e de mercadorias, abastecimento de água, ou coleta e tratamento de esgoto, por exemplo, é uma das principais razões da compactação da ocupação urbana. Para a carga urbana, a alta densidade urbana, de modo geral, significa uma maior necessidade de transporte de mercadorias para uma dada região, afetando, consequentemente, a capacidade de tráfego viário, devido ao aumento das movimentações dos veículos de carga. Assim, são necessárias estratégias para mitigar impactos negativos das altas densidades nos espaços urbanos mantendo sua qualidade e vitalidade social e econômica, assim como proporcionar condições adequadas ao abastecimento urbano. Já a expansão do uso misto do solo (empreendimentos com espaços planejados para uso residencial, comercial e de serviços combinados) em áreas predominantemente residenciais, poderá gerar afluxo adicional tanto de mercadorias, para abastecimento dos estabelecimentos comerciais, como de pessoas, ao acessar esses estabelecimentos para trabalhar ou adquirir produtos e serviços.

Nesse contexto, o objetivo geral desse artigo é identificar e analisar as inter-relações do transporte urbano de carga com o uso e ocupação do solo, desenvolvendo uma abordagem integrada da logística, do tráfego e do planejamento urbano. Inicialmente, investigou-se modelos disponíveis e apropriados ao objetivo pretendido, sendo identificados e analisados quatro modelos principais de origem internacional. Em seguida, foram realizadas a seleção, a adaptação e a aplicação do modelo Freturb em um recorte urbano na cidade de São Paulo. Trata-se de uma área com uso misto do solo e já adensada, do ponto de vista populacional e construído, localizada nos bairros de Santa Cecília e Higienópolis. Entretanto, o recorte urbano considerado constitui uma região ainda passível de adensamento, e é integrante de zona de influência dos Eixos de Estruturação da Transformação Urbana (EETU), segundo o Plano Diretor Estratégico (São Paulo, 2014). Assim, o recorte urbano constitui um estudo de caso pertinente à presente análise, tanto pelas características existentes já mensuráveis, quanto por possibilitar a proposição de recomendações para setores ainda passíveis de desenvolvimento, situações igualmente encontradas em outras áreas da cidade e mesmo em outras localidades urbanas no país.

\section{MODELOS DE APOIO À ANÁLISE INTEGRADA ENTRE O TRANSPORTE URBANO DE CARGA E O USO E OCUPAÇÃO DO SOLO}

Os aspectos de uso e ocupação do solo, relacionados à carga urbana permanecem relativamente ausentes nas abordagens do planejamento urbano. (Rodrigue, 2013 e Lindholm e Blinge, 2014). Prevalece a abordagem de aspectos referentes ao transporte de passageiros como paradigma, 
excluindo-se a problemática da movimentação de mercadorias na cidade. Dessa forma, a abordagem integrada entre a mobilidade urbana, de forma mais ampla, e o planejamento urbano é prejudicada, sobretudo no que se refere ao uso e ocupação do solo (FHWA, 2012 e Rodrigue et al., 2017). Taniguchi et al. (2016) apontam que é importante compreender e mitigar os impactos negativos do transporte urbano de mercadorias, principalmente os relacionados ao aumento dos congestionamentos, que afetam diretamente a qualidade do serviço oferecido pelas empresas de transporte e estimulam o aumento das emissões de gases efeito estufa e de poluentes.

Utilizar modelos como ferramenta de apoio ao planejamento urbano é fundamental para fornecer informações que darão suporte à determinação dos impactos urbanos e à tomada de decisões. Entretanto, embora haja diversos modelos de transporte urbano de carga, poucos estabelecem e avaliam a relação entre a logística urbana e o uso e ocupação do solo (Routhier e Toilier, 2007 e Dablanc et al., 2013). É comum, na literatura, aplicar modelos de transporte de pessoas, já contemplados em outras áreas, no planejamento do transporte urbano de carga (Rodrigue et. al., 2017). Essas iniciativas, porém, muitas vezes não têm alcançado grande eficácia, devido à insipiência dos problemas associados às atividades logísticas urbanas, à complexidade do sistema urbano de carga e à inexistência de base teórica, dados ou séries estatísticas confiáveis e completas (Dablanc, 2008 e Dablanc et al. 2013).

Quatro modelos foram identificados como pertinentes à presente análise, que não se referem àqueles aplicados exclusivamente à cadeia de suprimentos, mas que estabelecessem abordagens integradas entre aspectos da logística e o uso e ocupação do solo, trazendo o tema da carga urbana como tópico relevante no planejamento urbano. A tabela 1 representa, cronológica e sumariamente, as propriedades principais dos quatro modelos analisados: o GoodTrip (Holanda), o Wiver (Alemanha), o Freturb (França), e a associação desse último ao Dalsim (França). Allen et al. (2000), Russo e Comi (2010) e Ambrosini et al. (2013) apontam que esses modelos são comumente aplicados na Europa e seus resultados têm sido reconhecidos, progressivamente, como relevantes ao planejamento e à gestão da carga urbana em âmbito municipal, apoiando a tomada de decisão em processos logísticos e também no planejamento urbano.

Tabela 1: Modelos analisados

\begin{tabular}{|c|c|c|c|}
\hline Autores/modelo & Objetivos & O que determina & Local de aplicação \\
\hline $\begin{array}{l}\text { Boerkamps e } \\
\text { Binsbergen } \\
\text { (1999)/Goodtrip }\end{array}$ & $\begin{array}{l}\text { Estimar os efeitos das mudanças na } \\
\text { gestão da carga urbana e avaliar } \\
\text { seus impactos na logística urbana }\end{array}$ & $\begin{array}{l}\text { Calcula o volume de carga demandada } \\
\text { pelos tipos de estabelecimentos numa } \\
\text { determinada zona urbana }\end{array}$ & $\begin{array}{l}\text { Groningen e, } \\
\text { posteriormente, em } \\
\text { outras cidades da } \\
\text { Holanda }\end{array}$ \\
\hline $\begin{array}{l}\text { Meimbresse e } \\
\text { Sonntag (2001)/ } \\
\text { Wiver }\end{array}$ & $\begin{array}{l}\text { Apoiar a organização e o } \\
\text { dimensionamento da infraestrutura } \\
\text { urbana às atividades que envolvam } \\
\text { o transporte de carga urbana }\end{array}$ & $\begin{array}{l}\text { Estima a participação do tráfego } \\
\text { comercial no tráfego total e elabora } \\
\text { uma matriz de origem e destino do } \\
\text { tráfego de carga }\end{array}$ & $\begin{array}{l}\text { Diversas cidades da } \\
\text { Alemanha, Roma, } \\
\text { Lazio, Madri e } \\
\text { Bruxelas }\end{array}$ \\
\hline $\begin{array}{l}\text { Laboratório de } \\
\text { Economia dos } \\
\text { Transportes da } \\
\text { Universidade de } \\
\text { Lyon (2004)/Freturb } \\
\end{array}$ & $\begin{array}{l}\text { Diagnosticar e avaliar cenários do } \\
\text { transporte de carga urbana }\end{array}$ & $\begin{array}{l}\text { Estima o número de veículos atraídos } \\
\text { por uma área urbana, em função das } \\
\text { suas necessidades logísticas e permite } \\
\text { também calcular a utilização da rede } \\
\text { viária }\end{array}$ & $\begin{array}{l}43 \text { cidades da França, } \\
\text { Bruxelas e Zurique }\end{array}$ \\
\hline $\begin{array}{l}\text { Delaître e Routhier } \\
\text { (2010)/Freturb e } \\
\text { Dalsim }\end{array}$ & $\begin{array}{l}\text { Diagnosticar as operações de carga } \\
\text { e descarga nas áreas urbanas }\end{array}$ & $\begin{array}{l}\text { Quantifica entregas e coletas, tempo } \\
\text { médio da operação de carga e } \\
\text { descarga, distribuição de veículos de } \\
\text { carga ao longo do dia e simula as áreas } \\
\text { de carga e descarga }\end{array}$ & $\begin{array}{l}\text { Centro de } \\
\text { La Rochelle, França }\end{array}$ \\
\hline
\end{tabular}


O GoodTrip foi criado em 1998 e aplicado inicialmente em Groningen e, posteriormente, em outras cidades da Holanda. Seus pressupostos são baseados na ideia de que o ambiente urbano predispõe a demanda do transporte de pessoas e de cargas, enquanto a infraestrutura urbana e as opções de veículos de carga estabelecem as condições básicas de oferta dos níveis de serviço para atender a essa demanda (Boerkamps e Binsbergen, 1999). Boerkamps et al. (2000) apontam que a falta de otimização da infraestrutura pode resultar em congestionamentos que, consequentemente, podem predispor mudanças logísticas, tais como: mudança de rotas, horários de partida e, em longo prazo, mudanças na infraestrutura urbana. Dessa forma, o objetivo da aplicação do GoodTrip é diminuir simultaneamente o número de veículos comerciais na cidade e o número de quilômetros rodados, racionalizando e otimizando as viagens.

0 Wiver é fundamentado em pesquisas comportamentais realizadas em mais de 9.000 áreas das cidades de Munique, Berlim e Hamburgo, na Alemanha (Meimbresse e Sonntag, 2001). Para refletir os diferentes comportamentos das atividades logísticas em relação aos diversos setores da economia, o modelo calcula as viagens geradas por diferentes atividades econômicas em uma área urbana, podendo diferenciar o tráfego de carga de acordo com o tipo de atividade comercial, tipo de veículo e horários (Ambrosini et al., 2013). O Wiver é capaz de estimar a participação do tráfego comercial no tráfego total e elaborar um mapa de origem e destino do tráfego de carga, bem como é uma ferramenta de apoio para dimensionar e organizar a infraestrutura urbana para as atividades que envolvam o transporte urbano de carga. O Wiver tem sido aplicado em mais de quinze cidades na Alemanha, como também em Roma, Madri e Bruxelas.

Freturb objetiva diagnosticar e avaliar cenários do transporte urbano de carga. Foi desenvolvido pelo Laboratoire Aménagement Economie Transports de Université de Lyon (LAET-UdL), na França, para apoiar as administrações municipais francesas, com destaque à cidade de Lyon. De acordo com Routhier e Toilier (2013), o Freturb estima o número de veículos atraídos por uma área urbana, em função dos tipos e das densidades dos estabelecimentos comerciais instalados, assim como permite calcular a taxa de utilização da rede viária da área geográfica. Os resultados permitem avaliar a geração de movimentos de carga urbana e seu impacto na área urbana, mensurando, por exemplo, impactos da poluição atmosférica e sonora na cidade. A partir da utilização do Freturb em algumas cidades francesas, foi possível aprimorar os Planos de Mobilidade Urbana dessas cidades, integrando, com maior detalhamento e propriedade, as características e demandas logísticas (Ambrosini e Routhier, 2004).

Delaître e Routhier (2010) aplicaram no centro de La Rochelle, na França, o Freturb combinado com o modelo Dalsim (Delivery Areas and Logistics SIMulation), integrando, dessa forma, a análise da geração da movimentação de veículos de carga com o desempenho dos espaços dedicados para as operações de entrega e coleta em uma dada zona urbana, verificando, entre outros, possíveis impactos na fluidez do tráfego. A abordagem, basicamente, considera o tempo total que uma área de carga/descarga pode ser usada, dividido pela duração média de uma operação de carga/descarga. 0 resultado é a quantidade de entregas que pode ser alocada na área urbana, em um dado período de tempo, dando, portanto, uma estimativa de capacidade da área urbana, com suas densidades e usos, em realizar essas atividades. De acordo com Delaître e Routhier (2010), a ferramenta híbrida obteve resultados coerentes e eficientes para indicar os impactos das obstruções dos veículos de carga no tráfego em La Rochelle. Também foi utilizada para suportar projetos das áreas de carga/descarga nessa cidade, que, normalmente, são concebidos isoladamente por estabelecimento, sem a devida atenção às consequências geradas em escala micro ou macrourbana. 


\section{APLICAÇÃO DO FRETURB PARA ANÁLISE DAS INTER-RELAÇÕES DO TRANSPORTE URBANO DE CARGA COM O USO E OCUPAÇÃO DO SOLO}

A seleção do Freturb se fundamentou no fato de que a flexibilidade e a variedade dos indicadores fornecidos por essa ferramenta tornam o seu uso adequado às cidades com diferentes tamanhos, podendo, ainda, ser aplicado na escala micro urbana. Em conformidade com Ambrosini et al. (2013), o modelo tem se mostrado uma alternativa às cidades que têm escassos recursos financeiros, pois, para fazer os diagnósticos necessários, a ferramenta não demanda coleta de grandes quantidades de dados de entrada, reduzindo o seu custo de aplicação.

Além disso, Freturb inter-relaciona condicionantes e parâmetros inerentes à logística e ao tráfego com aqueles utilizados no planejamento urbano, sobretudo quanto à definição do uso e ocupação do solo e densidades urbanas. A sua aplicação possibilita desenvolver, no contexto de um estudo de caso na cidade de São Paulo, uma abordagem integrada e intersetorial de diferentes agentes relacionados ao tema (estabelecimentos comerciais, transportadores e autoridades municipais) e analisar o comportamento da logística associada à estrutura dos setores econômicos e ao uso e ocupação do solo de uma área urbana.

\subsection{O modelo Freturb}

O Freturb originou-se de um programa nacional da França, intitulada marchandises en ville (carga urbana), criado em 1993 pelo Ministério de Transporte e pela Agência de Controle de Energia e Meio Ambiente (ADEME). 0 propósito do programa era identificar e evitar os impactos ambientais do transporte urbano de carga, possibilitando, dessa forma, um desenvolvimento econômico urbano harmonioso (Routhier e Toilier, 2007). 0 desenvolvimento e a calibração do Freturb se realizaram a partir de um abrangente banco de dados estatísticos de duas pesquisas de Movimentação de Carga Urbana (MCU), ambas administradas pelo LAET-UdL, e que estão descritos em Ambrosini et al. (2013).

A primeira pesquisa de MCU foi realizada entre os anos 1994 e 1997, em cidades de diferentes portes: Marselha, Bordéus e Dijon, na época com, respectivamente, 1,1 milhão, 750 mil e 240 mil habitantes. Posteriormente, nos anos de 2010 e 2013, foi realizada uma nova coleta de dados da MCU em Paris e em Bordéus, respectivamente com 2,2 milhões e 240 mil habitantes, visando aprimorar o Freturb (Beziat, 2013). Routhier e Toilier (2007) afirmam que, com as referidas pesquisas, foi possível estabelecer relações entre os dados do comportamento econômico-espacial dos estabelecimentos (porte, perfil econômico e localização) com as operações de transportes da carga (quantidades e características dos movimentos, horários e escolha dos tipos de veículos). Assim, no Freturb, as características dos estabelecimentos determinam a geração e as características dos movimentos de entrega e/ou coleta de mercadorias em uma área urbana.

Bonnafous et al. (2013) apontam que os resultados das pesquisas de MCU não se diferenciaram significativamente de uma cidade para outra e, assim, a abordagem estatística, que veio a calibrar e a subsidiar a concepção do Freturb, mostrou-se relevante e coerente. A fundamentação dos elementos constituintes do Freturb, suas premissas e procedimentos de cálculo estão expostos em Routhier e Toilier (2007), Delaître e Routhier (2010), Ambrosini et al. (2013) e Bonnafous et al. (2013). Em resumo, os autores descrevem os diferentes elementos do modelo, bem como suas funcionalidades (módulos), além de discutirem os resultados da sua aplicação em alguns estudos de casos. 
Os resultados do Freturb são organizados em quatro módulos. Essencialmente, o primeiro módulo gera resultados para avaliação de movimentos de entrega e/ou coleta de mercadorias em uma área urbana. 0 segundo módulo estima o tempo de operação de carga/descarga no sistema viário urbano e suas condicionantes abrangem os tipos de veículos, o perfil da rota e a densidade populacional. 0 terceiro estima a hora-pico dos veículos de carga e está associado ao perfil da carga e dos estabelecimentos. 0 quarto, e último módulo, analisa a distribuição do tráfego de carga entre as áreas urbanas, e está relacionado com as densidades populacionais, tamanho dessas áreas e as densidades dos movimentos de carga (Ambrosini et al., 2013). Como a aplicação do Freturb no estudo de caso se restringiu a uma única área urbana, foram utilizados os três primeiros módulos do modelo.

O Freturb classifica os tipos de veículos de entrega e coleta em três categorias:

- Veículo Urbano de Cargas (VUC);

- Caminhões rígidos, semipesados e pesados. Os semipesados possuem eixo simples com rodas simples na carroceria, comprimento máximo de 14 metros e capacidade de até 6 toneladas. Os pesados têm eixo duplo na carroceria, com capacidade de 10 a 14 toneladas;

- Caminhões Articulados ou extrapesados, que podem ser engatados com carretas e semirreboques.

As condicionantes e definições matemáticas do Freturb estão descritas em Routhier e Toilier (2007) e Beziat (2013). As suas variáveis urbanas mais relevantes são estabelecidos por: (a) 45 subsetores econômicos; ( $p$ ) as premissas de 8 setores econômicos (indústria, escritórios, armazéns, comércios, etc); e, (o) quantidade de funcionários, organizados em intervalos de 0, 1, 2-5, 6-9, 10-19, 20-49, 50-99, 100-199, 200-299, etc. Dessa forma, a estimativa média da quantidade de movimentos é dada pela relação $n_{e}=\phi(a, p, o)$, em que $n_{e}$ é o número de movimentos por semana (entrega e/ou coleta) do estabelecimento $e$, em função das suas características $a, p, o$.

Routhier e Toilier (2007) detalham, ainda, os procedimentos necessários à definição dos dados de entrada necessários para a simulação do Freturb em áreas urbanas. Em suma, são necessários dois arquivos: o "Zona Urbana", que abrange as características geográficas e densidades urbanas do local em análise; e o SIRENE, que contém a base de dados estatísticos e econômicos de todos os estabelecimentos, seja público ou privado, em uma área urbana francesa e é gerido pelo Instituto Nacional de Estatísticas e Estudos Econômicos (INSEE), da França.

\subsection{O recorte urbano de Higienópolis e Santa Cecília}

A área de estudo compreende um recorte urbano de aproximadamente um quilômetro quadrado e está situada nos bairros de Higienópolis e Santa Cecília, no centro da cidade de São Paulo, conforme Figura 1. A seleção desse recorte urbano fundamentou-se por se tratar de uma área com uso misto, alta densidade demográfica e ter importantes avenidas e ruas comerciais, para as quais se mostrou pertinente aprofundar a análise das condições e impactos referentes à carga urbana. Além disso, de acordo com o Plano Diretor Estratégico de São Paulo, essa área integra zonas de influência dos EETU, possuindo, assim, incentivos para um possível aumento da densidade populacional e de edifícios com uso misto (São Paulo, 2014). 


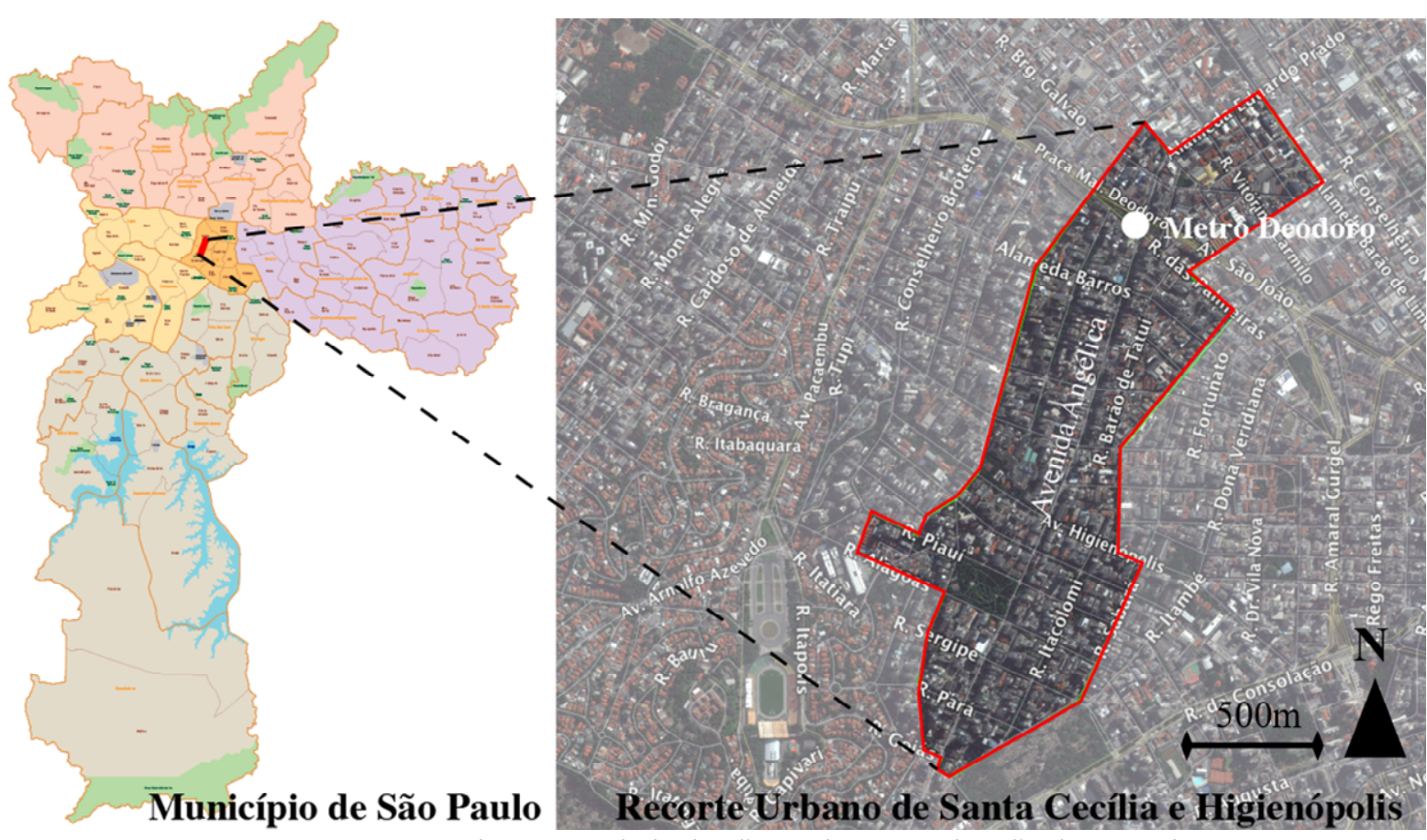

Figura 1: Recorte urbano na cidade de São Paulo para aplicação do Freturb

\subsection{Metodologia para a aplicação do Freturb no estudo de caso}

Na construção do arquivo "Zona Urbana", foram utilizados dados populacionais do Censo Demográfico (IBGE, 2010). As densidades demográficas dos distritos da Consolação e Santa Cecília são, respectivamente, 15.504 e 21.466 habitantes $/ \mathrm{km}^{2}$. A área de cada quadra foi obtida com dados oficiais da Secretaria Municipal de Urbanismo e Licenciamento da Prefeitura de São Paulo (São Paulo, 2019). Consequentemente, estimou-se a população por quadra e a população residente na área do estudo de caso, que é de aproximadamente 21.803 habitantes.

Para a modelagem e simulação do recorte urbano da cidade de São Paulo foi construído um SIRENE próprio, com o apoio do LAET-UdL, de acordo com as características da área estudada. Foram utilizados dados primários obtidos em coleta de campo realizada entre outubro de 2014 e janeiro de 2015, em conjunto com bases secundárias, para caracterização dos estabelecimentos do setor alimentício, totalizando 217 estabelecimentos, responsáveis pelo provimento de 4.258 postos de empregos. Esses dados foram sistematizados em uma planilha eletrônica do Microsoft Excel, seguindo critérios do formato original do SIRENE, e estão sumarizados na Tabela 2. Nos trabalhos de campo, foi aplicado um protocolo de entrevistas diretas aos estabelecimentos alimentícios da área de estudo, para caracterizá-los em função das suas atividades e porte, abrangendo as seguintes perguntas: $1^{\text {a }}$. pergunta, quantos funcionários o estabelecimento possui?; $2^{\mathrm{a}}$. pergunta, qual é a área, em $\mathrm{m}^{2}$, do estabelecimento?; $3^{\mathrm{a}}$. pergunta, quantas entregas são recebidas pelo estabelecimento por semana?

Os estabelecimentos alimentícios foram selecionados, no conjunto de estabelecimentos comerciais, por seu frequente uso diário pela população e por serem grandes demandadores de movimentações de mercadorias no recorte urbano. Outro aspecto favorável é o fato que os estabelecimentos alimentícios não possuem sazonalidades na oferta de empregos e na demanda de cargas, diferentemente de outros setores que aumentam a quantidade de funcionários e de mercadorias em períodos de maior consumo. Esse fato possibilita a coleta de dados na região 
estudada em qualquer época do ano. Alternativamente, seria possível consultar a RAIS - Relação Anual de Informações Sociais, base de dados do Ministério do Trabalho, que dispõe dos dados sobre a quantidade de funcionários e outras características de estabelecimentos comerciais.

Tabela 2: Sumário dos dados coletados em campo, dos estabelecimentos alimentícios situados na área de estudo

\begin{tabular}{|c|c|c|c|c|}
\hline Nomenclatura & Empregos & $\begin{array}{l}\text { Estabelecimentos } \\
\text { alimentícios }\end{array}$ & $\begin{array}{l}\text { Proporção dos } \\
\text { estabelecimentos (\%) }\end{array}$ & $\begin{array}{l}\text { Média de empregos } \\
\text { por estabelecimento }\end{array}$ \\
\hline Minimercados $\left(<400 \mathrm{~m}^{2}\right)$ & 128 & 11 & $5 \%$ & 12 \\
\hline Supermercados $\left(400<X<2500 m^{2}\right)$ & 221 & 3 & $1 \%$ & 74 \\
\hline Hipermercados (>2500 m²) & 268 & 2 & $1 \%$ & 134 \\
\hline Hortifrutis & 133 & 3 & $1 \%$ & 44 \\
\hline Açougues & 61 & 10 & $5 \%$ & 6 \\
\hline Padarias e bombonieres & 660 & 27 & $12 \%$ & 24 \\
\hline Adegas e empórios & 56 & 5 & $2 \%$ & 11 \\
\hline $\begin{array}{l}\text { Restaurantes, lanchonetes, fast-foods } \\
\text { e conveniências }\end{array}$ & 2.554 & 123 & $57 \%$ & 21 \\
\hline Bares, cafés e casa de sucos & 177 & 33 & $15 \%$ & 5 \\
\hline Total & 4.258 & 217 & $100 \%$ & 20 \\
\hline
\end{tabular}

Na modelagem do recorte urbano de São Paulo foi desconsiderado o decreto municipal $\mathrm{n}^{\mathrm{o}}$ 48.338, de 10 de maio de 2007, que estabelece restrições, das $9 \mathrm{~h}$ às $21 \mathrm{~h}$, para a circulação de veículos de carga conforme seu tamanho ou peso, por meio da Zona de Máxima Restrição de Circulação (ZMRC). Pretende-se identificar e analisar como ocorrem as densidades de movimentos de carga em função das características do uso e ocupação do solo (estabelecimentos); com a consideração da referida política, as inter-relações investigadas sofreriam uma simplificação em virtude da uniformização forçada da tecnologia veicular e a análise pretendida seria prejudicada.

\section{DISCUSSÃO DOS RESULTADOS DA MODELAGEM E SIMULAÇÃO DAS MOVIMENTAÇÕES DE CARGA ASSOCIADAS AOS ESTABELECIMENTOS ALIMENTÍCIOS}

Para apoiar a análise dos resultados referentes aos estabelecimentos alimentícios do recorte urbano na cidade de São Paulo, no ano de 2015, buscou-se realizar um comparativo com outras áreas urbanas com características próximas à área de estudo, no que tange a densidades demográficas e dimensões territoriais, e que já tivessem sido avaliadas pelo Freturb. Como não se identificou a aplicação prévia desse modelo em cidades brasileiras, foram pesquisadas áreas urbanas, no exterior, com as características mencionadas e com resultados simulados, disponibilizados pelo LAET-UdL. De acordo com esses critérios, selecionaram-se duas áreas urbanas situadas em cidades francesas: o centro de Lyon e o quarto arrondissement de Paris (mapeadas na Figura 2 e caracterizadas na Tabela 3). Assim, a referida comparação visou estabelecer a inter-relação das densidades de movimentos de carga com a densidade de estabelecimentos alimentícios e densidades populacionais, entre as respectivas áreas urbanas em questão.

Os resultados obtidos com Freturb foram interpretados segundo indicadores selecionados, organizados em três categorias:

- Uso e ocupação do solo:

- Densidades de empregos e de habitantes residentes;

- Densidade de estabelecimentos alimentícios;

- Média de empregos por estabelecimento alimentício;

○ Relação entre a movimentação de carga e a densidade de empregos. 
- Logística:

- Número de mercadorias recebidas/expedidas, por semana;

- Tipos de veículos de carga utilizados na movimentação de carga;

- Número de viagens de parada única, que consistem na distribuição direta de mercadorias de um determinado ponto de origem para um ponto de destino;

- Número de viagens com paradas múltiplas, nesse caso há uma interrupção ao menos um ponto de transbordo, para proporcionar um processo de agregação ou distribuição de mercadoria.

- Tráfego:

- Densidade de movimentos de carga no sistema viário, geradas pelos estabelecimentos alimentícios;

○ Hora-pico das movimentações da carga, relacionadas aos estabelecimentos alimentícios;

- Tempo de carga/descarga, abrangendo quatro formas de estacionar: 1) em "fila-dupla", quando o veículo estaciona na faixa de tráfego obstruindo o fluxo de veículos; 2) em local regulamentado; 3) em estacionamento privado do estabelecimento; 4) estacionado de forma proibida.

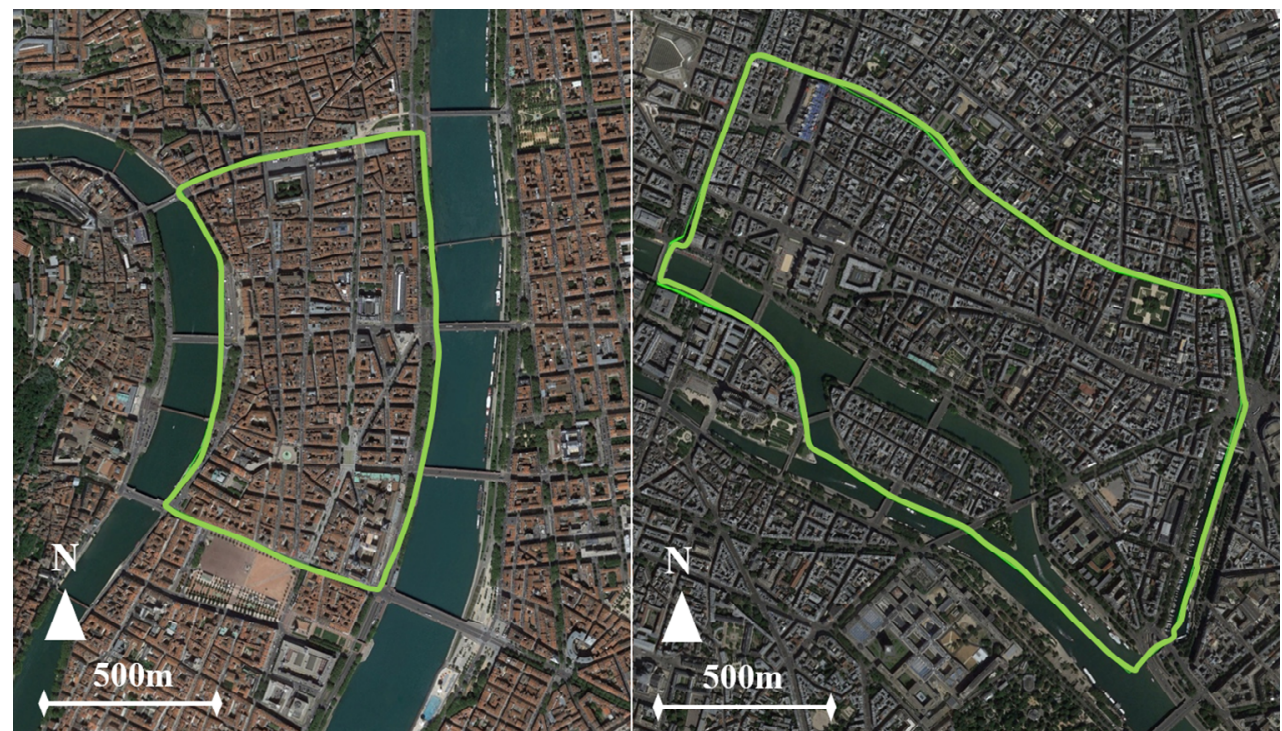

Figura 2: Recortes urbanos do centro de Lyon (esquerda) e do quarto arrondissement de Paris (direita)

\subsection{Aspectos de uso e ocupação do solo}

A Tabela 3 apresenta o sumário dos resultados obtidos na análise dos estabelecimentos alimentícios do recorte urbano, em macro escala, relativos a aspectos de uso e ocupação do solo. Analisando-a, é possível aferir que as três áreas urbanas, quando comparadas, possuem densidades de empregos muito parecidas. Porém, a quantidade de estabelecimentos alimentícios é muito superior nos recortes urbanos franceses. Outro aspecto pertinente é que o quarto arrondissement de Paris e o centro de Lyon são, respectivamente, cerca de 2,5 e 3 vezes (486 e 533 estabelecimentos alimentícios $/ \mathrm{km}^{2}$ ) mais densos em estabelecimentos alimentícios que o recorte urbano de São Paulo (185 estabelecimentos alimentícios $/ \mathrm{km}^{2}$ ). Porém, a densidade de movi- 
mentos de carga por estabelecimento alimentício nesse último (15 movimentos de carga/estabelecimento) é, praticamente, duas vezes maior que a mesma movimentação nos recortes urbanos franceses (8 movimentos de carga por estabelecimento).

Tabela 3: Resultados gerais sobre estabelecimentos alimentícios dos recortes urbanos analisados

\begin{tabular}{|c|c|c|c|c|}
\hline & \multirow[b]{2}{*}{ Unidade } & \multicolumn{3}{|c|}{ Configuração urbana de 2015} \\
\hline & & $\begin{array}{l}\text { São } \\
\text { Paulo }\end{array}$ & $\begin{array}{l}4^{\circ} . \text { arrs. de } \\
\text { Paris }\end{array}$ & $\begin{array}{l}\text { Centro } \\
\text { de Lyon }\end{array}$ \\
\hline Área & $\mathrm{Km}^{2}$ & 1,17 & 1,60 & 0,82 \\
\hline População & $\mathrm{n}^{\circ}$. habitantes & 21.803 & 30.675 & 11.247 \\
\hline Densidade Populacional & habitantes $/ \mathrm{km}^{2}$ & 18.580 & 19.172 & 13.664 \\
\hline Empregos & $\mathrm{n}^{\circ}$. empregos & 4.258 & 5.493 & 3.051 \\
\hline Densidades de empregos & empregos $/ \mathrm{km}^{2}$ & 3.628 & 3.433 & 3.707 \\
\hline Quantidade de estabelecimentos alimentícios & estabelecimentos alimentícios & 217 & 777 & 439 \\
\hline Densidade de estabelecimentos alimentícios & $\begin{array}{l}\text { estabelecimentos } \\
\text { alimentícios } / \mathrm{km}^{2}\end{array}$ & 185 & 486 & 533 \\
\hline $\begin{array}{l}\text { Quantidade de movimentos de carga por } \\
\text { semana }\end{array}$ & movimentos por semana & 3.258 & 6.069 & 3.387 \\
\hline Quantidade de movimento de carga por $\mathrm{km}^{2}$ & movimentos por semana $/ \mathrm{km}^{2}$ & 2.777 & 3.793 & 4.115 \\
\hline $\begin{array}{l}\text { Média de movimentos por estabelecimento } \\
\text { alimentício }\end{array}$ & movimentos/estabelecimento & 15 & 8 & 8 \\
\hline
\end{tabular}

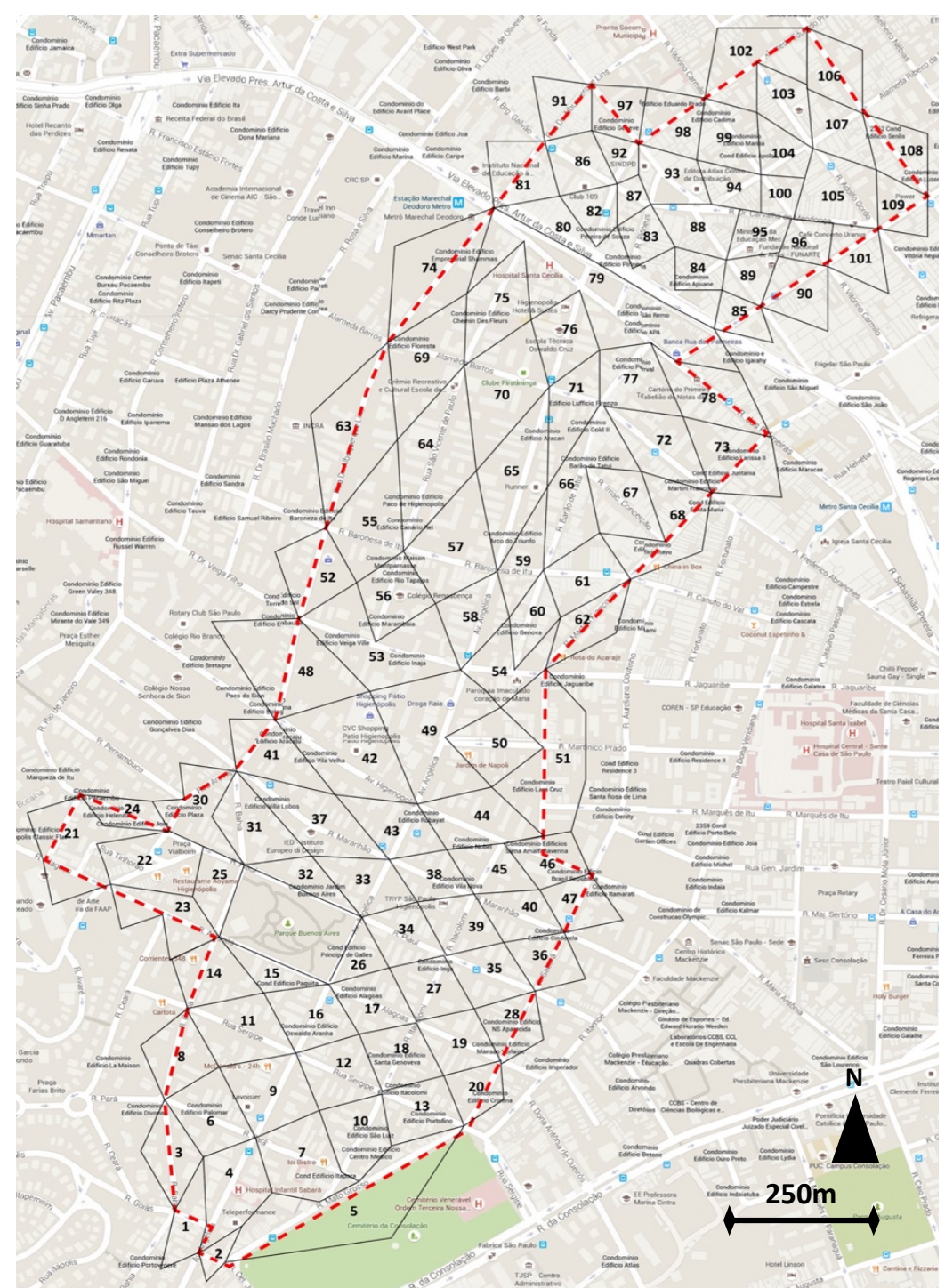

Figura 3: Zoneamento em "colmeia" do recorte urbano 
Para a análise micro urbana, foi feito um zoneamento em "colmeia" do recorte urbano da cidade de São Paulo, perfazendo um total de 109 zonas (Figura 3). A forma de "colmeia" visa colocar, na mesma zona, os estabelecimentos alimentícios que dão frente à mesma via e, assim, avaliar os impactos dos resultados causados por esses estabelecimentos em cada trecho viário, onde se dá a interação desses estabelecimentos com o espaço público.

No gráfico "A" da Figura 4, observam-se os picos dos resultados de empregos e movimentos de carga em cada zona da área estudada. As zonas 22, 51, 65, 78 são as áreas que mais geram movimentações de carga, cada uma, respectivamente, requer 192, 147, 203 e 204 movimentos de expedição e recebimento de carga por semana. Porém, quando comparamos empregos com movimentações de carga, nota-se que na zona 42 há 550 empregos e 110 movimentos; e, na zona 65, há 577 empregos e 203 movimentos de carga por semana. Assim, esses resultados mostram que as movimentações de carga, em uma área urbana, não variam, única e exclusivamente, de acordo com a quantidade de empregos, mas também ao perfil econômico e à dimensão do estabelecimento (Routhier e Toilier, 2007).

\subsection{Aspectos da logística}

Os resultados apontaram que os estabelecimentos alimentícios são polos atratores de mercadorias, pois $85 \%$ da movimentação total são para recebimento e 15\% para expedição de mercadorias. A coleta de dados em campo mostrou que apenas $4 \%$ dos estabelecimentos alimentícios da área de estudo são de grande porte, seguindo a tendência da região central da cidade de São Paulo, onde esses estabelecimentos são minoria. Contudo, os mesmos geram $22 \%$ das movimentações da carga no recorte urbano. Logo, a adição de empreendimento desse porte é uma iniciativa que requer atenção, do ponto de vista do impacto no tráfego em geral. Já os estabelecimentos alimentícios de pequeno porte perfazem $96 \%$ do total e geram $78 \%$ das movimentações de carga na área em análise. Além disso, observou-se que a maioria das entregas (82\%) foi realizada em roteiros com paradas múltiplas. Pressupõe-se, então, que a maior parte das entregas possui um pequeno volume, podendo ser consolidada em um mesmo caminhão ou utilizar veículos comerciais pequenos.

A simulação mostrou que a maior parte (58\%) das movimentações de cargas dos estabelecimentos alimentícios foi realizada por VUCs. Há também uma parte representativa de 35\% das movimentações de cargas que utiliza caminhões rígidos. Por fim, os veículos articulados representam apenas 7\% das movimentações de cargas.

\subsection{Aspectos do tráfego}

Para avaliar o desempenho do transporte urbano de carga e seus possíveis impactos negativos no tráfego da área de estudo, verificou-se a densidade de movimentos por zona. Em cada "zona" da colmeia (Figura 3), dividiu-se a soma dos movimentos de carga semanal pela área do trecho de via urbana correspondente, em metro quadrado $\left(\mathrm{m}^{2}\right)$. Os resultados, expostos no Gráfico "B", da Figura 4, mostraram que a zona mais afetada pelas movimentações de carga dos estabelecimentos alimentícios é a 81, com 0,12 movimentos de cargas por metro quadrado de via urbana na semana, seguida pelas zonas 78, 98, 01, 02, 11, 73, 102, 51, 106, 65 e 22.

A alta densidade de movimentos, associada à escassez de espaços urbanos destinados às operações de carga/descarga, incrementa os níveis de congestionamento, ruído, acidentes, poluentes e emissões de gases efeito estufa. 


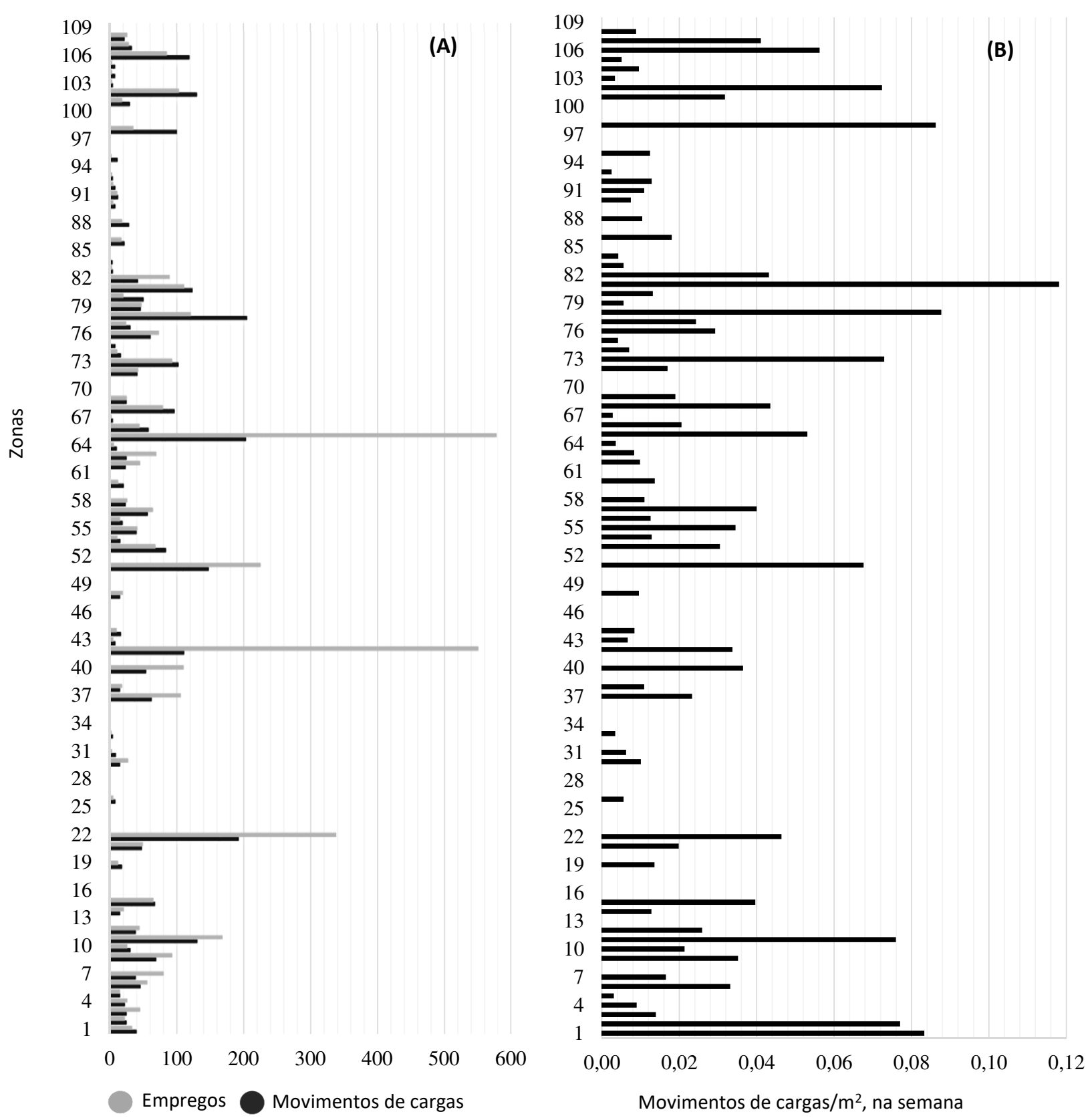

Figura 4: Gráfico "A", abordando a quantidade de empregos e movimentos de carga dos estabelecimentos alimentícios, por zona; gráfico "B", representando a densidade de movimentos de carga urbana, por zona, na área em estudo

Outro parâmetro analisado se refere aos horários do dia em que ocorrem as concentrações de circulação de veículos de carga, conforme mostra o gráfico da Figura 5. Observa-se que o período do dia em que houve a maior concentração de veículos rígidos e VUCs, foi das seis horas às onze horas da manhã; já das onze horas às treze horas, a quantidade de movimentos diminuiu, possivelmente por estarem no período do almoço e, por se tratar de estabelecimentos alimentícios, as operações de cargas e descargas são reduzidas. Posteriormente, no período da tarde, houve um pequeno incremento na movimentação de cargas, e durante a noite, a partir das 19 horas, a movimentação foi pouco representativa. Por outro lado, diferentemente dos veículos rígidos e VUCs, verifica-se que a movimentação dos veículos articulados se concentra no intervalo das cinco horas da manhã às nove e meia da manhã. 
Com a aplicação da restrição da ZMRC no recorte urbano, entende-se que os veículos rígidos e articulados, que juntos perfazem $42 \%$ das movimentações, teriam seu período de circulação reduzido. Sendo assim, essas respectivas distribuições de mercadorias teriam que ocorrer em períodos fora do intervalo de restrição e/ou serem realizadas por veículos menores, como os VUCs.

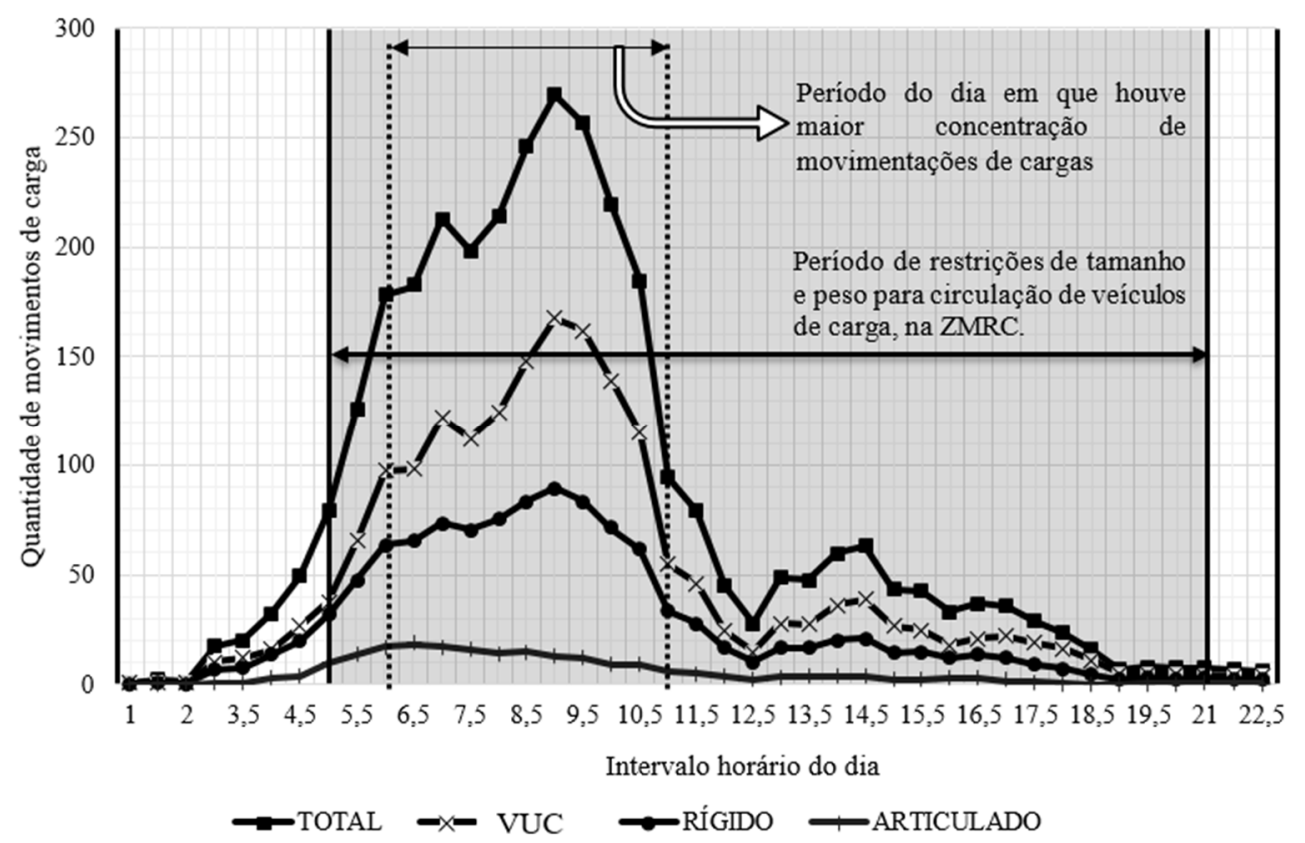

Figura 5: Hora-pico da movimentação de cargas nos estabelecimentos alimentícios, por tipo de veículo comercial e total, na área em estudo

Verificou-se, também, o tempo necessário para realizar as operações de carga/descarga, em horas por semana, e o tipo de estacionamento utilizado nessas operações. A simulação apontou que são despendidas 750 horas por semana para realizar os abastecimentos e as expedições de mercadorias nos estabelecimentos alimentícios. Metade das operações ocorre em paradas em "fila-dupla"; 30\%, em locais regulamentados; 13\%, em estacionamentos privados dos estabelecimentos alimentícios; e 7\%, de modo proibido. Estima-se, portanto, que são utilizadas 61 horas por dia, no recorte urbano estudado, para realizar operações de carga/descarga em desacordo com as normas de trânsito vigentes ("fila-dupla"/proibido).

Os estabelecimentos de pequeno porte, preponderantes na área de estudo (96\%), raramente ofertam áreas à operação de carga/descarga. Além disso, a limitação de espaço físico interno resulta em estoques reduzidos, necessitando de reabastecimento frequente e em quantidades pequenas. Dessa forma, esses tipos de estabelecimentos requerem da cidade mais espaços viários públicos destinados à operação de carga/descarga e os resultados confirmam que esses espaços não são suficientes para atender à demanda, no recorte urbano analisado.

Na cidade de São Paulo o estacionamento rotativo pago, denominado "Zona Azul", tem como objetivo racionalizar o uso do sistema viário em áreas adensadas e disciplinar o espaço urbano, das 41.832 vagas na cidade, apenas 4\% (1.737) são destinadas à Zona Azul para uso de caminhões (CET-SP, 2019). A escassez de vagas à operação de carga/descarga, principalmente na área central da cidade, traz problemas não apenas para o tráfego urbano, mas também para a realização das operações de carga/descarga, pois aumenta a distância média entre a vaga de estacionamento e o local da entrega. 


\subsection{Verificações dos resultados da modelagem in loco}

Tendo em vista verificar os resultados do Freturb na realidade da área urbana estudada, foi realizado um levantamento em campo, no dia 05 de dezembro de 2018 (quarta-feira), por meio de observações, registros e entrevistas com 45 estabelecimentos alimentícios simulados (20\% do total). Conforme indicado na modelagem, esse levantamento foi realizado no horário de maior concentração de movimentos de cargas, das 6h40m às 11h40m (Figura 5), e nas zonas da "colmeia" com as maiores densidades de movimentações de carga (Gráfico B, Figura 4). Decrescentemente, foram observadas as zonas: 81, 78, 01, 11, 102, 51, 65 e 22. Nessas áreas, além das observações visuais, foram efetuados, basicamente, os seguintes questionamentos aos estabelecimentos comerciais: período do dia e frequência semanal das entregas/coletas das mercadorias e tipos de vagas utilizadas para a realização das operações de carga/descarga.

Constatou-se que $100 \%$ dos entrevistados realizam suas operações de carga/descarga no período da manhã e, associado com a entrega matutina, 18\% dos entrevistados utilizam o período da tarde e 4,5\% o período noturno, para concluírem suas operações. Conforme aponta o registro da imagem (a) da Figura 6, há um consenso e uma organização na região, pelo abastecimento matutino; já o abastecimento noturno foi identificado apenas nos supermercados de grande porte. Cerca de $90 \%$ dos entrevistados indicaram que são necessários 2 ou 3 dias da semana para realizarem os seus abastecimentos semanais, costumeiramente nas segundas, terças e sextas-feiras. Contudo, não souberam informar a quantidade de entregas nesses dias. Sobre os tipos de paradas/estacionamentos para realizarem as operações de carga/descarga, observou-se uma quantidade insuficiente de vagas tipo "Zona Azul" para uso exclusivo de caminhões. Ainda, $60 \%$ dos estabelecimentos entrevistados informaram que realizam as operações em locais regulamentados, e apenas $13 \%$ possuem estacionamentos privados para a carga/descarga. Por fim, $66 \%$ do total reconhecem que utilizam também locais de parada/estacionamento em desacordo com as normas de trânsito vigentes para concluírem suas operações de carga/descarga.
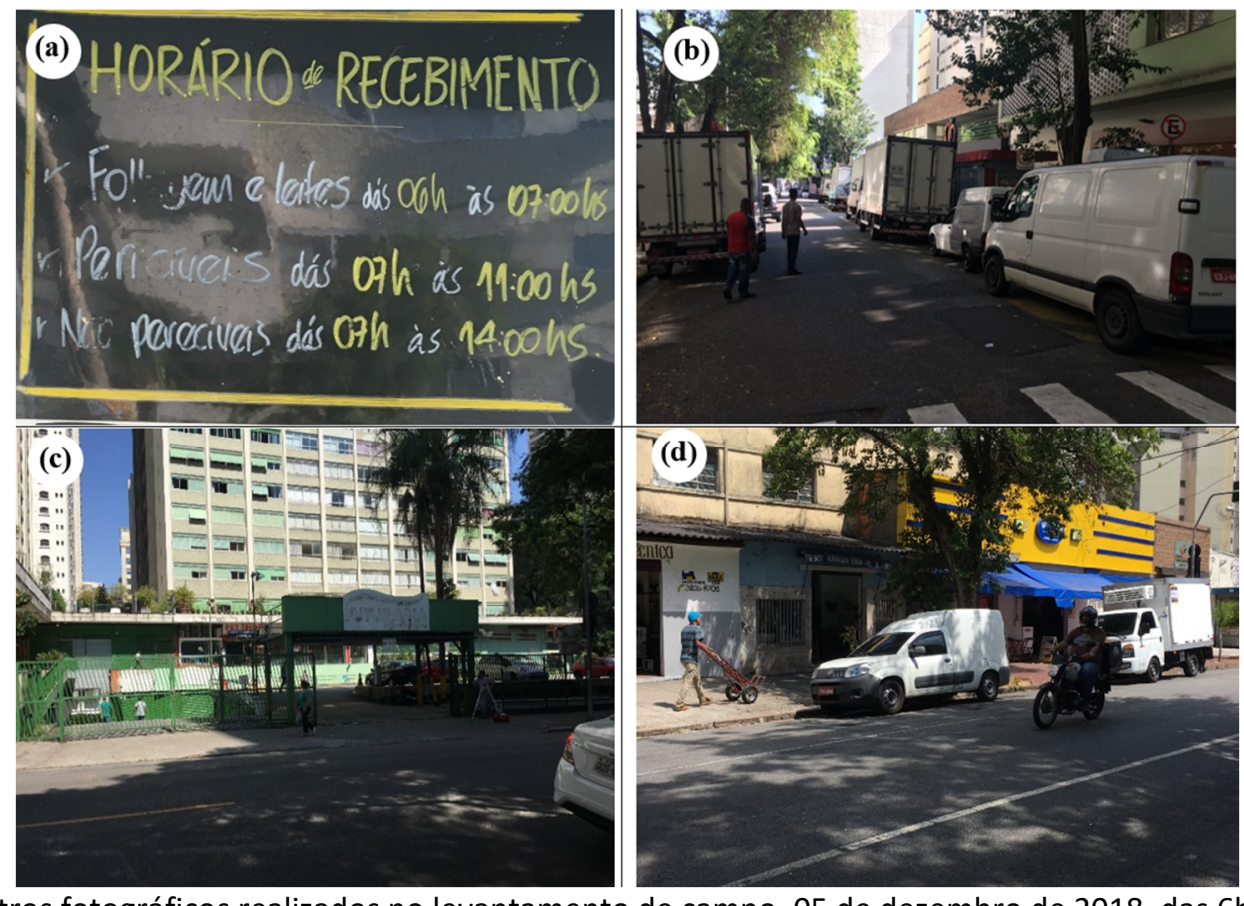

Figura 6: Registros fotográficos realizados no levantamento de campo, 05 de dezembro de 2018, das 6h40m às $11 \mathrm{~h} 40 \mathrm{~m}$ 
No que tange às verificações visuais das operações de carga/descarga dos estabelecimentos as zonas observadas mostram considerável movimentação de carga urbana. Contudo, durante as observações, destacaram-se três zonas: na zona 51, das 9 h40 às $10 \mathrm{~h} 10$ foi observada a maior movimentação de carga/descarga no levantamento (imagem (b), Figura 6), já os resultados da modelagem apontam que a hora-pico ocorre próximo a esse horário, das $9 \mathrm{~h}$ às $9 \mathrm{~h} 30 \mathrm{~m}$ (Figura 5); na zona 65, a movimentação de carga observada foi irrisória, pois o maior estabelecimento dessa zona estava encerrado (imagem (c), Figura 6). Por fim, na zona 102 houve pouca movimentação de veículos de carga devido às proibições de estacionamentos no viário. Contudo nas ruas adjacentes se observou uma razoável quantidade de veículos de carga realizando suas entregas com "carrinho-de-mão" (imagem (d), Figura 6).

\section{ANÁLISE INTEGRADA ENTRE USO E OCUPAÇÃO DO SOLO, LOGÍSTICA E TRÁFEGO}

Verificou-se que o uso e ocupação do solo condicionam diversos aspectos inerentes aos sistemas logísticos e geram, juntamente com este, uma série de impactos sobre o tráfego, em uma dada região urbana. Assim, o reconhecimento das inter-relações existentes e da interdependência dos parâmetros urbanos é fundamental. Primeiramente, porque é possível inserir condicionantes da logística urbana nas legislações de uso e ocupação do solo do município como um todo, e nos projetos de desenvolvimento urbano de distritos, no que tange à previsão de áreas comerciais (setor econômico, porte do estabelecimento e número de empregos gerados), para que este também se torne um tema tratado no planejamento urbano. Em seguida, a própria regulamentação do uso do sistema viário precisa ser adequada em função das atividades e localizações dos estabelecimentos comerciais; por outro lado, limitações da capacidade viária também devem ser consideradas quando se planeja, por meio da política de uso e ocupação do solo, a expansão de estabelecimentos comerciais e o adensamento urbano.

O esquema da Figura 7 sumariza como os elementos dos aspectos do uso e ocupação do solo, da logística e do tráfego urbano interagem no espaço urbano, com base na análise dos resultados da aplicação do Freturb, no recorte urbano estudado. A demanda por mercadorias é vinculada a parâmetros do uso e ocupação do solo, como o adensamento de estabelecimentos comerciais, de empregos e, ainda, ao tamanho e ao perfil econômico desses estabelecimentos. Quando esses parâmetros se alteram, a quantidade e o perfil da movimentação da carga urbana também são alterados. Adicionalmente, áreas urbanas com alta densidade populacional e com alto índice de motorização (automóveis por habitante) predispõem a diminuição da oferta de espaços urbanos adequados às operações de carga/descarga. Consequentemente, estimula-se o aumento de paradas dos veículos de carga em desacordo com as normas de trânsito vigentes, intensificando os congestionamentos, os acidentes e as emissões de gases efeito estufa e de poluentes. Observa-se, também, que certos tipos de veículos comerciais de carga e certos tipos de parada influenciam na determinação da hora-pico e nos tipos de operação de carga/descarga em uma dada área urbana.

0 recorte urbano analisado é integrante de área de influência dos EETU, segundo o Plano Diretor Estratégico de São Paulo, que incentiva, nessas áreas, adensamento populacional e de empregos, assim como empreendimentos com uso misto (portanto, novas áreas comerciais e de serviços). Entende-se, dessa forma, que esta política urbana, se bem-sucedida, virá a demandar mais atividades logísticas, incrementando os impactos negativos verificados. Por outro lado, como verificado no estudo comparativo do recorte urbano em São Paulo com as áreas urbanas 
em Lyon e Paris, parece ser possível também eficientizar as próprias atividades logísticas, pois, naqueles locais, há maior adensamento de estabelecimentos comerciais atendidos, proporcionalmente, como menos movimentações de carga.
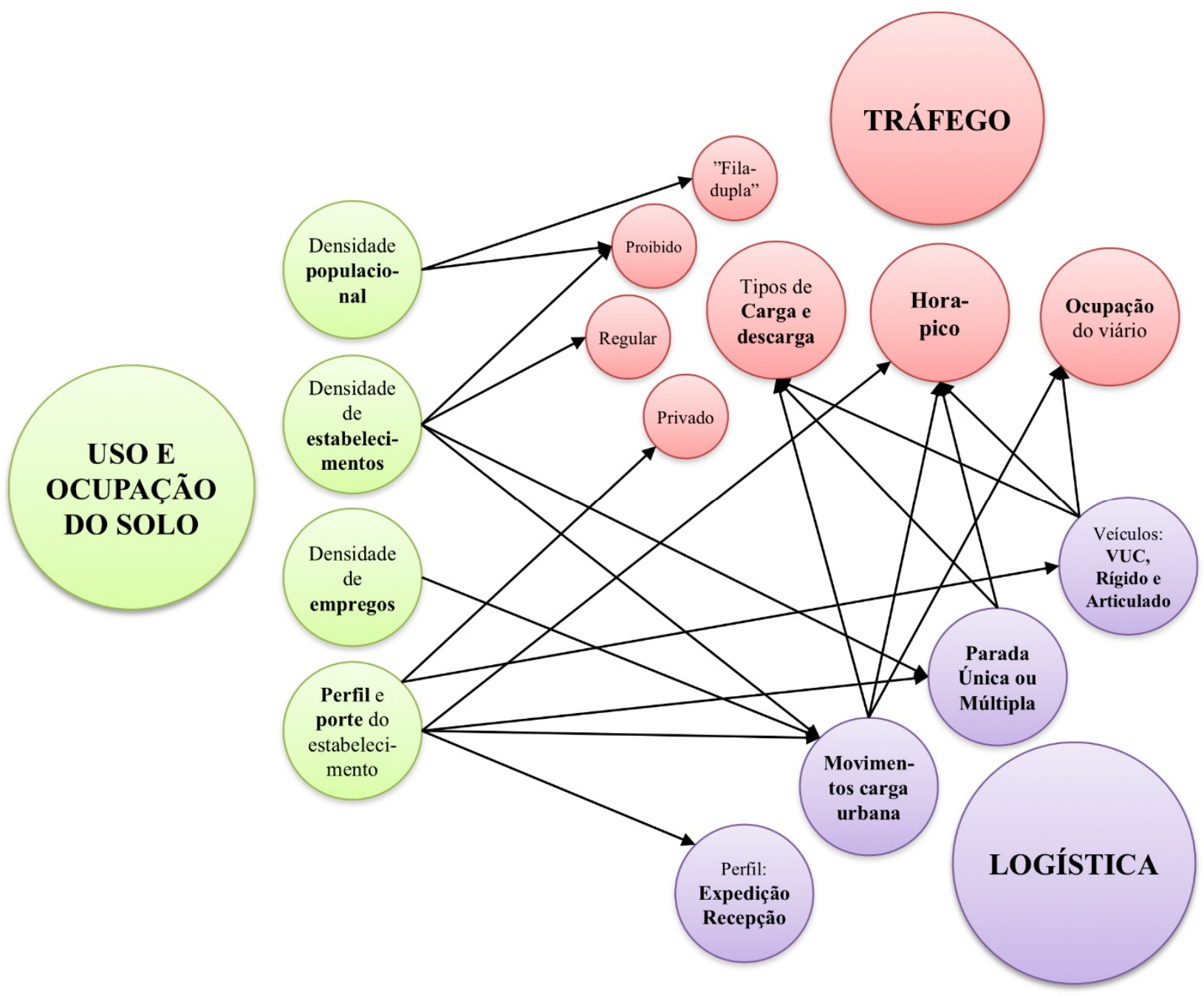

Figura 7: Interação dos aspectos do uso e ocupação do solo, logística e tráfego no espaço urbano

Dessa forma, um plano de adensamento urbano e de diversificação do solo prescinde de adequações nas próprias operações logísticas, visando a um melhor desempenho global das intervenções previstas. Além disso, a própria diretriz de incentivo ao uso misto precisa ser melhor qualificada e detalhada, pois se verificou, nesse estudo, que as tipologias dos estabelecimentos comerciais, seu porte e setor econômico, geram diferentes demandas logísticas. Exemplificando, estabelecimentos de menor porte demandam transporte de mercadorias em menor quantidade, motivando uma dinâmica de abastecimento em paradas múltiplas, com maiores necessidades espaços viários públicos destinados às operações de carga/descarga. Assim, planejar o desenvolvimento do uso misto, suas características e portes, impacta tanto o desenvolvimento urbano quanto a logística de carga, e deve ser objeto de planejamento intersetorial.

\section{CONCLUSÕES}

Este trabalho identificou e analisou modelos dedicados à avaliação integrada do transporte urbano de carga e dos parâmetros urbanísticos de uso e ocupação do solo. Os modelos são utili- 
zados por planejadores urbanos e agentes logísticos nos processos de decisão, visando à eficiência e à eficácia do sistema urbano de carga e da estruturação do território urbano, de suas atividades econômicas e de suas políticas públicas de transporte e uso e ocupação do solo, gerando redução dos impactos na dinâmica intra-urbana.

A comparação dos resultados da análise em macro escala do recorte urbano da cidade de São Paulo com os recortes do centro de Lyon e do quarto arrondissement de Paris permitiu analisar, de forma comparativa, a empregabilidade e a densidade de movimentos da carga nas regiões de acordo com o perfil econômico dos estabelecimentos. Essa comparação apontou que a área estudada na cidade de São Paulo necessita de mais movimentações de carga em relação às duas áreas francesas, e exige mais do sistema viário urbano, e/ou é suprida por sistemas logísticos menos organizados.

Já a simulação em escala micro urbana permitiu identificar as áreas urbanas que apresentam elevada densidade de movimentação de carga, que, consequentemente, ocasionarão aumento das adversidades urbanas na região, como o aumento dos níveis de congestionamento, de ruídos, de acidentes, de emissões de poluentes e de gases efeito estufa.

A aplicação do Freturb em um recorte urbano da cidade de São Paulo propiciou, também, realizar o diagnóstico da inter-relação de condicionantes e parâmetros inerentes à logística e ao tráfego (tipos de veículos comerciais, hora-pico, condições de carga/descarga e movimentações) com aqueles utilizados no planejamento urbano, em especial, aos que constituem elementos de definição do uso e ocupação do solo (densidades de estabelecimentos, empregos e habitantes e, também, as dimensões e perfil econômico dos estabelecimentos).

Constatou-se, ainda, que o número de funcionários, o perfil econômico e o porte dos estabelecimentos alimentícios predeterminam certos elementos da logística, como as densidades de movimentos da carga e os tipos de veículos e de paradas utilizados nas entregas e coletas. Esses elementos da logística, por sua vez, predispõem o aumento de tempo de carga/descarga em uma área urbana. A ausência de espaços, quer sejam públicos ou privados, para a operação de carga/descarga, bem como a alta densidade de habitantes com alto índice de motorização, contribui para o aumento da parada indevida de veículos de carga em "fila-dupla" e em local proibido.

Também se constatou as interdependências entre diversos parâmetros do planejamento urbano (perfil econômico, número e porte dos estabelecimentos comerciais alimentícios, número de empregos e de habitantes), da logística (tipos de veículos comerciais, condições de carga/descarga e quantidades de movimentações) e do tráfego, mostrando que esses aspectos impactam diretamente na organização e na racionalização do uso do espaço urbano.

Dessa forma, reconhecem-se, por meio deste trabalho, os parâmetros de controle intersetoriais, nos quais a abordagem integrada de logística, tráfego e uso e ocupação do solo pode ser desenvolvida e, finalmente, internalizada no planejamento e nos projetos de desenvolvimento urbano. Os resultados da modelagem mostraram os impactos negativos decorrentes de um planejamento desassociado desses três setores, quer seja na escala das quadras urbanas e entorno dos estabelecimentos comerciais, quanto em congestionamentos viários, e no próprio processo de abastecimento dos estabelecimentos.

Ademais, integrar aspectos e parâmetros da logística, do tráfego e do uso e ocupação do solo requer uma abordagem multiescalar. Ou seja, não basta planejar sistemas integrados apenas em nível regional, metropolitano ou mesmo municipal; é preciso adentrar na microescala urbana, 
na qual se dá a interação do sistema logístico com o estabelecimento comercial, e onde características de uso e ocupação do solo e desenho urbano são condicionantes fundamentais do desempenho das próprias atividades logísticas e das condições de uso e qualidade do próprio espaço urbano, para esta e outras funções urbanas.

Assim, o reconhecimento dessas inter-relações e o planejamento articulado de suas condicionantes são fundamentais para o planejamento das cidades, sobretudo nas áreas em adensamento urbano, quando se faz necessária a compatibilização de usos, densidades, serviços e infraestrutura urbana, bem como nas definições intersetoriais constantes das políticas urbanas e dos instrumentos urbanísticos.

\section{AGRADECIMENTOS}

À Coordenação de Aperfeiçoamento de Pessoa de Nível Superior (CAPES), pelo apoio para o desenvolvimento da pesquisa, por meio da concessão de bolsa de estudo.

Ao Laboratoire Aménagement Economie Transports de Université de Lyon (LAET-UdL), pelo suporte obtido em todas as etapas da simulação com o Freturb.

\section{REFERÊNCIAS}

Allen, J.; Anderson, S.; Browne, M.; Jones, P. (2000) A framework for considering policies to encourage sustainable urban freight traffic and goods/services flows. Transport Studies Group, University of Westminster, London, England. 4 volumes.

Ambrosini, C.; Gonzalez-Feliu, J.; Toilier, F. (2013) A design methodology for scenario-analysis in urban freight modelling. European Transport, v. 54, n. 7, p. 1-21.

Ambrosini, C.; Routhier, J. L. (2004) Objectives, Methods and Results of Survey Carried out in the Field of Urban Freight Transport: An International Comparison. Transport Reviews: A Transnational Transdisciplinary Journal, v. 24, n.1, p. 57-77. DOI: $10.1080 / 0144164032000122343$

Beziat, A. (2013) French cities' urban freight surveys. 1st Scientific and Technical Workshop, Bologna.

Boerkamps, J.; Binsbergen, A. V. (1999) Good Trip - A new approach for modelling and evaluation of urban goods distribution. In Taniguchi E., Thompson R.G. (eds.). City logistics I, Institute for City Logistics, Kyoto, p. 175-186.

Boerkamps, J.; Binsbergen, A. V.; Bovy, P. H. L. (2000) Modeling behavioral aspects of urban freight movement in supply chains. Transportation Research Record: Journal of the Transportation Research Board, v. 1725, n. 1, p. 17-25. DOI: 10.3141/1725-03

Bonnafous, A.; Gonzalez-Feliu, J.; Routhier, J. L. (2013) An alternative UGM paradigm to OD matrices: the FRETURB model. In: WCTR 2013 Rio de Janeiro, p. 21.

CET-SP - Companhia de Engenharia de Tráfego da Cidade de São Paulo. (2019). Mapa Zona Azul. A zona azul em números. Disponível em:<http://www.cetsp.com.br/consultas/zona-azul/mapa-zona-azul/mapa-zona-azul.aspx>. Acesso em: 14 fevereiro 2019.

Dablanc, L. (2008) Urban Goods Movement and Air Quality, Policy and Regulation Issues in European Cities. Journal of Environmental Law, v. 20, n. 2, p. 245-266, D0I: 10.1093/jel/eqn005

Dablanc, L.; Giuliano, G.; Holliday, K.; O’Brien, T. (2013) Best Practices in Urban Freight Management: Lessons from an International Survey. TRB, Transportation Research Record, v. 2379, n. 1, p. 29-38. DOI: 10.3141/2379-04

Dablanc, L.; Frémont, A. (2015) La métropole logistique. Le transport des marchandises et le territoire des grandes villes. Paris, Armand Colin, $312 \mathrm{p}$.

Delaître, L.; Routhier, J. L. (2010) Mixing two French tools for delivery areas scheme decision making. Procedia-Social and Behavioral Sciences, v. 2, n. 3, p. 6274-6285. DOI: 10.1016/j.sbspro.2010.04.037

Federal Highway Administration - FHWA (2012). FHWA freight and land use handbook. Washington, DC: US Department of Transportation.

IBGE - Instituto Brasileiro de Geografia e Estatística. (2010) Censo Demográfico 2010. Disponível em: <http://www.ibge.gov.br/home/estatistica/populacao/censo2010/>. Acesso em: 14 fevereiro 2019.

Lindholm, M.; Blinge, M. (2014). Assessing knowledge and awareness of the sustainable urban freight transport among Swedish local authority policy planners. Transport Policy, v. 32, p. 124-131. DOI: 10.1016/j.tranpol.2014.01.004

Marins, K. R. C. C.; Romero, M. A. (2012) Integração de condicionantes de morfologia urbana no desenvolvimento de metodologia para planejamento energético urbano. Ambiente Construído, Porto Alegre, v. 12, n. 4, p. 117-137. DOI: $10.1590 /$ S1678-86212012000400009

Meimbresse, B.; Sonntag, H. (2001) Modelling urban commercial traffic with the model WIVER, In: Patier, D. (ed.) L'intégration des marchandises dans le système des déplacements urbains, p. 93-106, Lyon: Laboratoire d'Economie des Transports.

Rodrigue, J-P (2013) Urban Goods Transport. In: UNHABITAT Planning and Design for Sustainable Urban Mobility: Global Report on Human Settlements 2013, United Nations Human Settlements Programme, London: Earthscan.

Rodrigue, J-P.; Dablanc, L.; Giuliano, G. (2017) The freight landscape Convergence and divergence in urban freight distribution. Journal of Transport and Land Use, v. 10, n. 1, p. 557-572. DOI: 10.5198/jtlu.2017.869 
Routhier, J. L.; Toilier, F. (2007) FRETURB V3, A Policy Oriented Software of Modelling Urban Goods Movement. 11th WCTR, Jun 2007, Berkeley, United States.

Routhier, J. L.; Toilier, F. (2013) Freturb V3.0 Diagnostic and Simulation Software for Urban Freight Transport. Laboratory of Economy of Transport, University of Lyon.

Russo, F., Comi, A. (2010) A classification of city logistics measures and connected impacts. Procedia-Social and Behavioral Sciences, v. 2, n. 3, p. 6355-6365. DOI: 10.1016/j.sbspro.2010.04.044

São Paulo (Cidade). Lei no.16.050, de 31 de julho de 2014. Política de Desenvolvimento Urbano e o Plano Diretor Estratégico. São Paulo: Diário Oficial da Cidade de São Paulo, 01 de agosto de 2014, ano 59, n. 140, p. 1-352.

São Paulo (Cidade) Secretaria Municipal de Urbanismo e Licenciamento. Dados Estatísticos. Disponível em:<http://www.prefeitura.sp.gov.br/cidade/secretarias/desenvolvimento_urbano/dados_estatisticos/>. Acesso em: 14 fevereiro 2019.

Silva, T. C. M.; Marins, K. R. C. C. (2014) Discutindo o papel do transporte de carga no planejamento urbano: contextualização e comparativo conceitual. In: XXVIII Congresso Nacional de Pesquisa e Ensino em Transporte da ANPET, 2014, Curitiba, Paraná.

Taniguchi, E.; Thompson, R. G.; Yamada, T. (2016) New opportunities and challenges for city logistics. Transportation Research Procedia, v. 12, p. 5-13. DOI: 10.1016/j.trpro.2016.02.004 